\begin{tabular}{|l|}
\hline Access this article online \\
\hline Quick Response Code: \\
\hline Website: \\
Www.jponline.org \\
\hline DOI: \\
10.4103/JLP.JLP_75_18 \\
\hline
\end{tabular}

Department of Community Medicine and General Surgery, LHMC and Associated Hospitals, New Delhi, India

Address for correspondence: Dr. Manish Kumar Goel, Department of Community Medicine, LHMC and Associated Hospitals, Connaught Place - 110 001, New Delhi, India. E-mail: drmanishgoel2000

@yahoo.co.in

Submission: 28-05-2018 Accepted: 28-09-2018

\title{
Gallstone disease and quantitative analysis of independent biochemical parameters: Study in a tertiary care hospital of India
}

\author{
Deepak Dhamnetiya, Manish Kumar Goel, BalRaj Dhiman, Om Prakash Pathania
}

\begin{abstract}
:
INTRODUCTION: Gallstone disease (GSD) represents a significant burden for health-care systems worldwide and is one of the most common disorders among patients presenting to emergency rooms with abdominal discomfort. This study was aimed to know the association of biochemical parameters and development of GSD.

MATERIALS AND METHODS: We conducted a case-control study from January 2013 to December 2013 among patients attending outpatient department of general surgery at a tertiary care hospital of Delhi, North India; we recruited 120 cases and the same number of controls in the study. Data collection for both cases and controls was done on a self-designed pretested interview schedule and all the patients were investigated for relevant biochemical parameters. Logistic regression was used for univariate and multivariate analyses to find out different correlates and analyze the independent effects of these correlates on GSD.
\end{abstract}

RESULTS: We have included 120 cases and the same number of age- and sex-matched controls in the study and final analysis. Almost $70 \%$ of the cases were females and $30 \%$ were males. In multivariate logistic regression, we have found maximum significant association with serum total cholesterol (odds ratio [OR]: 1.013 , confidence interval [Cl]: $1.003-1.024, P=0.041$ ) followed by low-density lipoprotein (LDL) cholesterol (OR: 1.017, Cl: 1.001-1.034, $P=0.04$ ) and triglycerides (OR: 1.009, Cl: 1.001-1.018, $P=0.049)$. Fasting blood sugar $(P=0.18)$, high-density lipoprotein cholesterol $(P=0.07)$, aspartate transaminase $(P=0.21)$, alanine transaminase $(P=0.29)$, and total bilirubin $(P=0.13)$ were not found to be independently associated with GSD.

CONCLUSION: Biochemical parameters such as plasma total cholesterol, triglycerides, and LDL cholesterol level were independently associated with GSD.

Key words:

Biochemical parameters, case-control study, gallstone disease

\section{Introduction}

Crs allstone disease (GSD) represents a Isignificant burden for health-care systems worldwide and is one of the most common disorders among patients presenting to emergency rooms with abdominal discomfort. ${ }^{[1]}$ In India, the prevalence of gallstones ranges from $6 \%$ to $9 \%$ in the adult population. ${ }^{[2,3]}$ Age, This is an open access journal, and articles are distributed under the terms of the Creative Commons Attribution-NonCommercial-ShareAlike 4.0 License, which allows others to remix, tweak, and build upon the work non-commercially, as long as appropriate credit is given and the new creations are licensed under the identical terms.

For reprints contact: reprints@medknow.com gender, ethnicity, diet, and sedentary lifestyle influence the prevalence of GSD..$^{[4-6]}$ It is important to address these factors as early as possible. Different biochemical parameters might play a great role in the early diagnosis of GSD, as change in levels of these parameters might have a strong association with the risk factors, hence the development of GSD. There are few studies showing the association of biochemical parameters and development of GSD;[5,6]

\footnotetext{
How to cite this article: Dhamnetiya D, Goel MK Dhiman B, Pathania OP. Gallstone disease and quantitative analysis of independent biochemical parameters: Study in a tertiary care hospital of India. J Lab Physicians 2018;10:448-52.
} 
therefore, this study was aimed to know the association of biochemical parameters and development of GSD.

\section{Materials and Methods}

To address the above objective, we conducted a case-control study from January 2013 to December 2013 among patients attending the outpatient department (OPD) of general surgery at a tertiary care hospital of Delhi, North India. Sample size was calculated using Fleiss formula ${ }^{[7]}$ and assuming cases-to-controls ratio of 1:1 and for power of $80 \%$ and level of significance of $95 \%$ with an assumption of prevalence of some less common risk factors as $14 \% .{ }^{[8]}$ The final calculated sample size was 116 patients in each group, though we recruited 120 cases and the same number of controls in the study. The study participants were selected from OPD of general surgery.

\section{Cases}

Consecutive ultrasonography-confirmed cases of GSD aged 20 years or more presenting in the OPD were enrolled in the study, until the sample size was met. Seriously ill GSD patients, patients who had psychiatric problems, and patients who did not give consent were excluded from the study.

\section{Controls}

Patients above 20 years of age presented to surgical OPD and diagnosed negative for gallstones by ultrasonography were taken as controls and matched for age and sex. Pregnant females, diagnosed cases of other hepatobiliary disease, and renal stones were excluded from the study.

\section{Data collection}

Data collection for both cases and controls was done on a self-designed pretested interview schedule which assessed the sociodemographic profile, personal history, medical history and dietary intake, and physical examination including anthropometry. All the patients were investigated for biochemical parameters, i.e., fasting blood sugar (FBS), triglycerides, total cholesterol, high-density lipoprotein cholesterol (HDL), low-density lipoprotein cholesterol (LDL), aspartate transaminase (AST), alanine transaminase (ALT), and total bilirubin, with a standard cutoff. ${ }^{[9]}$ Physical activity $^{[10]}$ and anthropometric indices were calculated for all cases and controls using standard definitions. ${ }^{[11]}$ Dietary assessment was done using the $24 \mathrm{~h}$ recall method and Food Frequency Questionnaire as a cross-check, and calculations for nutrient intake were done using the Indian Council of Medical Research standards. ${ }^{[12]}$

\section{Data management and statistical analysis}

Data were recorded in MS Excel, and Epi Info 7 is statistical software for epidemiology developed by Centers for
Disease Control and Prevention (CDC) in Atlanta, Georgia (US) and licensed as public domain was used for statistical analysis. Observations have been described in terms of mean, range, and standard deviation for continuous data and in terms of percentages/proportions for categorical data. For comparison of characteristics among the study participants, independent Student's " $t-$ " test was used. Logistic regression was used for univariate and multivariate analyses to find out different correlates and analyze the independent effects of these correlates on GSD.

\section{Ethical considerations}

Ethical approval for this study was provided by the Institutional Ethical Committee of Lady Hardinge Medical College and Associated Hospitals (letter no. LHMC/ECHR/2014/180), and also the informed consent was obtained from each of the study participant.

\section{Results}

We have included 120 cases and the same number of age- and sex-matched controls in the study and final analysis. Almost $70 \%$ of the cases were females and 30\% were males. Proportion of cases in each age group is increasing as the age group increases [Table 1].

Comparison of characteristics using independent Student's " $t$-" test showed that there were significant differences in the mean value of body mass index (BMI); waist circumference; waist/hip ratio ( $\mathrm{W} / \mathrm{H}$ ratio); daily intake of calories, proteins, and fats; FBS; total cholesterol; triglycerides; HDL; LDL; AST; and ALT in cases as compared to control group except for mean levels of total bilirubin [Table 2].

Univariate logistic regression analysis of anthropometric variables showed that sedentary physical activity and high $\mathrm{W} / \mathrm{H}$ ratio were significantly more in cases as compared to controls. Significantly more cases were overweight or obese (BMI $\left.\geq 23 \mathrm{~kg} / \mathrm{m}^{2}\right)$ as compared to controls [Table 3]. After analyzing the dietary variables, the nonvegetarian diet found to be strongly associated with the occurrence of GSD. Cases consumed significantly more than recommended calories and fats as compared to controls. Intake of less protein than recommended significantly associated with the development of GSD [Table 3].

Univariate analysis of biochemical parameters showed that HDL level was lower in cases as compared to controls but not statistically significant. Levels of FBS, total cholesterol, triglycerides, and LDL were significantly higher in cases vis a vis controls. Levels of AST, ALT, and total bilirubin were higher in cases as compared to controls but not statistically significant [Table 3]. 
Table 1: Distribution of cases according to age and sex

\begin{tabular}{lccc}
\hline Age group & Male (\%) & Female (\%) & Total $(\%)$ \\
\hline $20-30$ & $6(16.2)$ & $8(9.6)$ & $14(11.7)$ \\
$31-40$ & $8(21.6)$ & $19(22.9)$ & $27(22.5)$ \\
$41-50$ & $9(24.3)$ & $27(32.5)$ & $36(30)$ \\
$51-65$ & $14(37.8)$ & $29(34.9)$ & $43(35.8)$ \\
Total & $37(30.8)$ & $83(69.2)$ & $120(100)$ \\
\hline
\end{tabular}

Table 2: Comparison of characteristics among the study participants using independent Student's $t$-test

\begin{tabular}{lcccc}
\hline \multirow{2}{*}{ Variable } & \multicolumn{2}{c}{ Mean \pm SD } & \multirow{t}{*}{$\boldsymbol{t}$} & $\boldsymbol{P}$ \\
\cline { 2 - 3 } & Case & Control & & \\
\hline BMI $\left(\mathrm{kg} / \mathrm{m}^{2}\right)$ & $23.20 \pm 3.15$ & $21.95 \pm 2.81$ & 3.25 & $<0.001$ \\
WC $(\mathrm{cm})$ & $75.79 \pm 7.07$ & $73.49 \pm 6.09$ & 2.70 & 0.007 \\
W/H ratio & $0.80 \pm 0.06$ & $0.77 \pm 0.05$ & 3.82 & $<0.001$ \\
Calorie intake (kcal) & $2193 \pm 376$ & $2006 \pm 420$ & 3.64 & $<0.001$ \\
Fat intake (g) & $32.10 \pm 6.81$ & $29.23 \pm 5.94$ & 3.48 & $<0.001$ \\
Protein intake (g) & $51.78 \pm 7.34$ & $54.53 \pm 9.27$ & -2.54 & 0.01 \\
FBS (mg/dl) & $98.39 \pm 19.51$ & $92.48 \pm 16.64$ & 2.52 & 0.01 \\
Total cholesterol (mg/dl) & $183.49 \pm 34.44$ & $163.73 \pm 27.79$ & 4.89 & $<0.001$ \\
Triglycerides (mg/dl) & $169.06 \pm 63.23$ & $149.78 \pm 19.44$ & 3.20 & 0.002 \\
HDL (mg/dl) & $40.90 \pm 8.13$ & $41.30 \pm 7.77$ & -2.20 & 0.03 \\
LDL (mg/dl) & $123.86 \pm 19.66$ & $112.98 \pm 18.80$ & 4.38 & $<0.001$ \\
AST (IU/L) & $40.36 \pm 7.78$ & $35.87 \pm 10.84$ & 3.68 & $<0.001$ \\
ALT (IU/L) & $47.68 \pm 9.50$ & $44.38 \pm 8.99$ & 2.76 & 0.006 \\
Total bilirubin & $0.93 \pm 0.42$ & $0.84 \pm 0.41$ & 1.67 & 0.09 \\
\hline
\end{tabular}

$\mathrm{SD}=$ Standard deviation, $\mathrm{BMl}=$ Body mass index, $\mathrm{WC}=$ Waist circumference, $\mathrm{W} / \mathrm{H}=$ Waist/hip ratio, $\mathrm{FBS}=$ Fasting blood sugar, $\mathrm{HDL}=$ High-density lipoprotein, LDL = Low-density lipoprotein, AST = Aspartate transaminase, $\mathrm{ALT}=$ Alanine transaminase

We further analyzed biochemical parameters using multivariate logistic regression analysis to find the independent association of these parameters with GSD and found significant association with serum total cholesterol followed by LDL cholesterol and triglycerides. Other biochemical parameters such as FBS, HDL cholesterol, AST, ALT, and total bilirubin were not found to be independently associated with GSD [Table 4].

\section{Discussion}

In our study, we tried to find the association between different risk factors, i.e., age, gender, obesity, sedentary lifestyle, dietary intake, lipid profile, and development of GSD. We found that the proportion of GSD was increased with increasing age, and this has been corroborated by several other authors. ${ }^{[13,14]}$ A higher proportion of GSD was seen in females $(69.2 \%)$, which might be because estrogen increases biliary cholesterol secretion causing cholesterol supersaturation of bile, rendering it lithogenic, the same findings were observed by other authors. ${ }^{[10,13]}$

Personal risk factors such as sedentary lifestyle, overweight or obesity, and high $\mathrm{W} / \mathrm{H}$ ratio were significantly associated with the development of GSD, reason for such finding may be because obesity increases cholesterol synthesis, biliary cholesterol secretion, and cholesterol supersaturation; similar results were seen in other studies, ${ }^{[10,15,16]}$ whereas in few studies, no significant association was seen between these personal risk factors and GSD. ${ }^{[17,18]}$

Univariate analysis of dietary factors shows that nonvegetarian diet increases the risk of gallstones by more than three folds; the reason for such finding may be because in Indian population, preparation of nonvegetarian diet generally involves lots of fat as compared to nonvegetarian preparation in other parts of world. Hence, in our settings, high fat usage may be the reason for having the significant association of nonvegetarian diet with GSD, whereas other studies showed no significant association between the type of diet and gallstones. ${ }^{[10,19]}$ Daily intake of high calories and high fats favors the formation of gallstones, and high protein diet shows protective effect against gallstone formation; similar results were seen in other studies. ${ }^{[15,16]}$ Whereas, in some studies, intake of calories and fats was not significantly associated with GSD. ${ }^{[20]}$ Reason for such finding may be because high energy intake leads to obesity and high fat intake leads to loss of bile acids in feces and decreased bile acid pool, promoting supersaturation of bile and rendering it more lithogenic. Proteins exerted an inhibitory effect on biliary cholesterol crystallization, which is the determinant step in gallstone genesis.

High fasting blood sugar level was significantly associated with the development of GSD as seen by univariate analysis; it might be because people with diabetes have hypotonic gallbladder and the bile of patients with diabetes mellitus is supersaturated with cholesterol; this is corroborated with the findings of De Santis et al. ${ }^{[21]}$

We have also analyzed the association of different biochemical parameters in the development of GSD. We found that high level of plasma triglycerides, total cholesterol, and LDL cholesterol were found to be significantly associated with the development of GSD. In contrast to this, low level of plasma HDL cholesterol was found to be a risk factor for the development of GSD but not statistically significant; similar findings were seen in some other studies, ${ }^{[22-24]}$ whereas some showed that hyperlipidemia, plasma HDL cholesterol, and plasma triglycerides were not significantly associated with GSD ${ }^{[10,14]}$ Liver enzymes (AST and ALT) and total bilirubin were not significantly associated with gallstone formation, consistent with the findings of Sun et al. ${ }^{[5]}$

We performed multivariate logistic regression analysis to find the independent association of biochemical 
Table 3: Univariate analysis of anthropometric variables, dietary intake, and biochemical parameters among the study participants

\begin{tabular}{|c|c|c|c|}
\hline Variable & Cases (120) & Controls (120) & OR $(95 \% \mathrm{CI})$ \\
\hline \multicolumn{4}{|l|}{ Physical activity } \\
\hline Sedentary & 74 & 44 & $2.78(1.65-4.69)$ \\
\hline Mod/vigorous & 46 & 76 & \\
\hline \multicolumn{4}{|l|}{ BMI } \\
\hline High & 68 & 51 & $1.77(1.06-2.95)$ \\
\hline Normal & 52 & 69 & \\
\hline \multicolumn{4}{|l|}{$\mathrm{W} / \mathrm{H}$ ratio } \\
\hline High & 31 & 14 & $2.64(1.32-5.26)$ \\
\hline Normal & 89 & 106 & \\
\hline \multicolumn{4}{|l|}{ Diet } \\
\hline Nonvegetarian & 71 & 37 & $3.25(1.91-5.53)$ \\
\hline Vegetarian & 49 & 83 & \\
\hline \multicolumn{4}{|l|}{ Calories } \\
\hline$>\mathrm{RDA}$ & 48 & 33 & $1.76(1.02-3.02)$ \\
\hline$\leq \mathrm{RDA}$ & 72 & 87 & \\
\hline \multicolumn{4}{|l|}{ Proteins } \\
\hline$>$ RDA & 18 & 34 & $0.45(0.24-0.85)$ \\
\hline$\leq \mathrm{RDA}$ & 102 & 86 & \\
\hline \multicolumn{4}{|l|}{ Fats } \\
\hline$>\mathrm{RDA}$ & 74 & 51 & $2.18(1.3-3.65)$ \\
\hline$\leq \mathrm{RDA}$ & 46 & 69 & \\
\hline \multicolumn{4}{|l|}{ FBS } \\
\hline Normal & 83 & 99 & $0.48(0.26-0.88)$ \\
\hline High & 37 & 21 & \\
\hline \multicolumn{4}{|l|}{ Total cholesterol } \\
\hline Normal & 95 & 116 & $7.69(2.56-25.00)$ \\
\hline High & 25 & 4 & \\
\hline \multicolumn{4}{|l|}{ Triglycerides } \\
\hline Normal & 47 & 82 & $3.33(1.96-5.56)$ \\
\hline High & 73 & 38 & \\
\hline \multicolumn{4}{|l|}{ HDL } \\
\hline Normal & 90 & 101 & $1.78(0.93-3.33)$ \\
\hline Low & 30 & 19 & \\
\hline \multicolumn{4}{|l|}{ LDL } \\
\hline High & 94 & 109 & $2.70(1.28-5.88)$ \\
\hline Normal & 26 & 11 & \\
\hline \multicolumn{4}{|l|}{ AST } \\
\hline Normal & 95 & 104 & $1.69(0.86-3.45)$ \\
\hline High & 25 & 16 & \\
\hline \multicolumn{4}{|l|}{ ALT } \\
\hline Normal & 97 & 105 & $1.67(0.82-3.33)$ \\
\hline High & 23 & 15 & \\
\hline \multicolumn{4}{|l|}{ Total bilirubin } \\
\hline Normal & 105 & 111 & $1.75(0.74-4.17)$ \\
\hline High & 15 & 9 & \\
\hline
\end{tabular}

$\mathrm{BMI}=$ Body mass index, $\mathrm{WC}=$ Waist circumference,

$\mathrm{W} / \mathrm{H}=$ Waist/hip ratio, $\mathrm{FBS}=$ Fasting blood sugar, $\mathrm{HDL}=$ High-density lipoprotein, $\mathrm{LDL}=\mathrm{Low}$-density lipoprotein, AST = Aspartate transaminase,

$\mathrm{ALT}=$ Alanine transaminase, $\mathrm{OR}=$ Odds ratio, $\mathrm{Cl}=$ Confidence interval

parameters with the development of GSD. We have found that total cholesterol, triglycerides, and LDL cholesterol level were independently associated with GSD, whereas, no significant association was found by Tîrziu et al. ${ }^{[24]}$ Other variables such as FBS, HDL
Table 4: Multivariate logistic regression analysis of biochemical parameters with gallstone disease among the study participants

\begin{tabular}{|c|c|c|c|c|c|}
\hline \multirow[t]{2}{*}{ Variable } & \multirow[t]{2}{*}{ Coefficient $\beta$} & \multirow[t]{2}{*}{ Adjusted OR } & \multicolumn{2}{|c|}{$95 \% \mathrm{Cl}$} & \multirow[t]{2}{*}{$P$} \\
\hline & & & Lower & Upper & \\
\hline FBS & 0.011 & 1.011 & 0.995 & 1.028 & 0.18 \\
\hline Total cholesterol & 0.013 & 1.013 & 1.003 & 1.024 & 0.041 \\
\hline Triglycerides & 0.009 & 1.009 & 1.001 & 1.018 & 0.049 \\
\hline $\mathrm{HDL}$ & -0.034 & 0.966 & 0.931 & 1.003 & 0.07 \\
\hline LDL & 0.017 & 1.017 & 1.001 & 1.034 & 0.043 \\
\hline AST & 0.021 & 1.021 & 0.988 & 1.055 & 0.21 \\
\hline ALT & 0.018 & 1.018 & 0.985 & 1.052 & 0.29 \\
\hline Total bilirubin & 0.555 & 1.741 & 0.844 & 3.591 & 0.13 \\
\hline
\end{tabular}

$\mathrm{OR}=$ Odds ratio, $\mathrm{Cl}=$ Confidence interval, $\mathrm{FBS}=$ Fasting blood

sugar, $\mathrm{HDL}=$ High-density lipoprotein, $\mathrm{LDL}=\mathrm{Low}$-density lipoprotein,

$\mathrm{AST}=$ Aspartate transaminase, $\mathrm{ALT}=$ Alanine transaminase

cholesterol, AST, ALT, and total bilirubin though associated were not statistically significant for GSD.

As total cholesterol, triglycerides, and LDL cholesterol level were independently associated with the development of GSD, individuals those have raised levels of these biochemical parameters with or without dietary or lifestyle risk factors should be screened for these biochemical parameters. Furthermore, routine screening of these biochemical parameters in adult patients presenting to hospitals with different diseases might help in the early diagnosis of gallstone disease. Individuals with raised levels of total cholesterol, triglycerides, and LDL cholesterol should be screened regularly for the early diagnosis of GSD and also prevention of complications because of the sudden onset of severe gallstone problem.

Maintenance of controlled plasma levels of total cholesterol, triglycerides, and LDL cholesterol might help in the prevention of GSD.

\section{Conclusion}

Individuals who are overweight or obese and having sedentary lifestyle should be advised for screening of GSD. Vegetarian diet with recommended calories and fats and high protein diet should be promoted. Moreover, several biochemical parameters such as plasma total cholesterol, LDL cholesterol, and triglycerides were independently associated with GSD and should be assessed routinely in patients with the suspicion of GSD. This might help in better counseling and prevention of development of GSD in these individuals.

\section{Financial support and sponsorship} Nil.

\section{Conflicts of interest}

There are no conflicts of interest. 


\section{References}

1. Hung SC, Liao KF, Lai SW, Li CI, Chen WC. Risk factors associated with symptomatic cholelithiasis in Taiwan: A population-based study. BMC Gastroenterol 2011;11:111.

2. Khuroo MS, Mahajan R, Zargar SA, Javid G, Sapru S. Prevalence of biliary tract disease in India: A Sonographic study in adult population in Kashmir. Gut 1989;30:201-5.

3. Unisa S, Jagannath P, Dhir V, Khandelwal C, Sarangi L, Roy TK, et al. Population-based study to estimate prevalence and determine risk factors of gallbladder diseases in the rural Gangetic Basin of North India. HPB (Oxford) 2011;13:117-25.

4. Shaffer EA. Epidemiology and risk factors for gallstone disease: Has the paradigm changed in the $21^{\text {st }}$ century? Curr Gastroenterol Rep 2005;7:132-40.

5. Sun H, Tang H, Jiang S, Zeng L, Chen EQ, Zhou TY, et al. Gender and metabolic differences of gallstone diseases. World J Gastroenterol 2009;15:1886-91.

6. Liu CM, Tung TH, Chou P, Chen VT, Hsu CT, Chien WS, et al. Clinical correlation of gallstone disease in a Chinese population in Taiwan: Experience at Cheng Hsin general hospital. World J Gastroenterol 2006;12:1281-6.

7. Fleiss JL, Levis B, Paik CM. Statistical Methods for Rates and Proportions. $3^{\text {rd }}$ ed. New York: Wiley InterScience; 2003. p. 89-93.

8. National Family Health Survey for India. $3^{\text {rd }}$ ed. Mumbai, India: International Institute for Population Science; 2006.

9. Kasper DL, Fauci AS, Hauser SL, Longo DL, Jameson JL, Loscalzo J. Harrison's Principles of Internal Medicine. $19^{\text {th }}$ ed. New York: McGraw Hill Education; 2015. Available from: https://www.cmecde.com/download-harrison-principlesof-internal-medicine-19 ${ }^{\text {th }}$-edition-pdf/. [Last accessed on 2018 May 22]

10. Sachdeva S, Khan Z, Ansari MA, Khalique N, Anees A. Lifestyle and gallstone disease: Scope for primary prevention. Indian J Community Med 2011;36:263-7.

11. World Health Organization. The Asia Pacific Perspective; Redefining Obesity and its Treatment. Available from: http: / / www.wpro.who.int/nutrition/documents / docs / Redefiningobesity.pdf. [Last accessed on 2014 Dec 17].

12. National Institute of Nutrition (Indian Council of Medical Research).
Dietary Guidelines for Indians-A Manual. Available from: http:/ / www.ninindia.org/DietaryGuidelinesforNINwebsite.pdf. [Last accessed on 2018 Aug 09].

13. Palermo M, Berkowski DE, Córdoba JP, Verde JM, Giménez ME. Prevalence of cholelithiasis in Buenos Aires, Argentina. Acta Gastroenterol Latinoam 2013;43:98-105.

14. Xu Q, Tao LY, Wu Q, Gao F, Zhang FL, Yuan L, et al. Prevalences of and risk factors for biliary stones and gallbladder polyps in a large Chinese population. HPB (Oxford) 2012;14:373-81.

15. Kumari DJ, Krishna SH. Role of body mass index, physical activity and nutrients in cholelithiasis in Guntur, Andhra Pradesh. J Hum Ecol 2010;31:151-5.

16. Al-Kayatt MK, Al-Youzbaki DB. Sociological risk factors in development of gallstones for childbearing age women. Iraqi J Community Med 2008;2:97-103.

17. Misciagna G,Centonze S, Leoci C, Guerra V, Cisternino AM, Ceo R, et al. Diet, physical activity, and gallstones - a population-based case-control study in Southern Italy. Am J Clin Nutr 1999;69:120-6.

18. Sahi T, Paffenbarger RS Jr., Hsieh CC, Lee IM. Body mass index, cigarette smoking, and other characteristics as predictors of self-reported, physician-diagnosed gallbladder disease in male college Alumni. Am J Epidemiol 1998;147:644-51.

19. Walcher T, Haenle MM, Mason RA, Koenig W, Imhof A, Kratzer W, et al. The effect of alcohol, tobacco and caffeine consumption and vegetarian diet on gallstone prevalence. Eur J Gastroenterol Hepatol 2010;22:1345-51.

20. Alsaif MA. Variations in dietary intake between newly diagnosed gallstone patients and controls. Pak J Nutr 2005;4:1-7.

21. De Santis A, Attili AF, Ginanni Corradini S, Scafato E, Cantagalli A De Luca C, et al. Gallstones and diabetes: A case-control study in a free-living population sample. Hepatology 1997;25:787-90.

22. Channa NA, Khand F, Ghanghro AB, Soomro AM. Quantitative Analysis of serum lipid profile in gallstone patients and controls. Pak J Anal Environ Chem 2010;38:59-65.

23. Gomati A, Elafi S, Rafe H, Abimbola EO, Willido AA, Sahitha R. Study on the risk factors for gallbladder diseases in El-Khoms teaching hospital, Libya. Asian J Trop Med Public Health 1990;2:1-4.

24. Tîrziu S, Bel S, Bondor CI, Acalovschi M. Risk factors for gallstone disease in patients with gallstones having gallstone heredity. A case-control study. Rom J Intern Med 2008;46:223-8. 